\title{
Baía de Sepetiba: uma aventura perigosa
}

\section{Sepetiba Bay: a dangerous adventure}

\author{
${ }^{1}$ Gisele Braga Torqueti torquetigaldino@gmail.com \\ ${ }^{1}$ Vânia Lúcia Muniz de Pádua
}

\section{RESUMO}

\begin{abstract}
A Baía de Sepetiba localizada no litoral Sul do Rio de Janeiro, na região sudeste do Brasil, é um local considerado excelente para grandes investimentos, que passou ao longo das últimas décadas, de Sertão Carioca à área industrial, resultando em conflitos socioambientais. Este trabalho apresenta uma análise da situação de degeneração social e ambiental na Baía de Sepetiba, incluindo o estudo do nível de conhecimento de estudantes de Ensino Médio da região, sobre os danos causados ao seu cotidiano e ao próprio meio ambiente, devido às atividades antrópicas para o desenvolvimento econômico. Além disso, foi estudada a taxa de mortalidade por câncer em locais entorno da Baía de Sepetiba. Os resultados revelam que os estudantes da Baía de Sepetiba amostrados têm pouco entendimento sobre as alterações provocadas pelos empreendimentos locais, e que estes têm sério impacto sobre a qualidade de vida e saúde da população, neste último caso, observado no aumento da taxa de mortalidade por câncer nos locais ambientalmente mais impactados. Estes dados em conjunto poderão servir como instrumento de conscientização para proteção e preservação do meio ambiente, bem como promoção da melhoria da qualidade de vida, com sustentabilidade.
\end{abstract}

Palavras-chave: Baía de Sepetiba. Escola. Câncer. Educação ambiental.

\begin{abstract}
Sepetiba Bay, located on the south coast of Rio de Janeiro, in the southeastern region of Brazil, is considered an excellent place for large investments, which has passed over the last decades, from Sertão Carioca to an industrial area, resulting in social and environmental conflicts. This paper presents an analysis of the situation of social and environmental degeneration in Sepetiba Bay, including the study of the level of knowledge of local high school students, about the damage caused to their daily lives and their own environment by the anthropic activities for economic development. In addition, the cancer mortality rate in locations around Sepetiba Bay was studied. The results show that the students of Sepetiba Bay have little understanding about the changes caused by local enterprises, and that these have a serious impact on the quality of life and health of the population, in the latter case, observed in the increase in the mortality rate by cancer in the most environmentally impacted sites. These data together can serve as an awareness tool for protection and preservation of the environment, as well as promoting the improvement of quality of life, with sustainability.
\end{abstract}

Keywords: Baía de Sepetiba. School. Cancer. Environmental education.

1 Fundação Centro Universitário Estadual da Zona Oeste - Laboratório de Biotecnologia Ambiental. 


\section{INTRODUÇÃO}

A Baía de Sepetiba está localizada no litoral Sul do estado do Rio de Janeiro, na região sudeste do Brasil, abrangendo o território de 15 municípios fluminenses, sendo que Engenheiro Paulo de Frontin, Itaguaí, Japeri, Mangaratiba, Paracambi, Queimados e Seropédica, estão totalmente inseridos na bacia, e, Rio Claro, Miguel Pereira, Mendes, Piraí, Nova Iguaçu, Rio de Janeiro, Vassouras e Barra do Piraí, encontram-se com apenas parte de seu território nela englobada (CBH Guandu, 2013).

A bacia hidrográfica contribuinte à Baía de Sepetiba tem uma superfície de 2.654 km2 e possui dois conjuntos fisiográficos distintos: o Domínio Serrano representado por montanhas e escarpas da vertente oceânica da Serra do Mar e pelos maciços costeiros (Maciço da Pedra Branca, Mendanha, Ilha da Marambaia); e o Domínio da Baixada, representado por uma extensa planície flúvio-marinha (RONCARATI \& CARELLI, 2012). A entrada de água do mar se dá através de passagens e canais existentes entre o continente e as Ilhas de Itacuruçá, Jaguanum e Pombeba. É caracterizada por ser uma laguna costeira semifechada conectada ao mar na porção leste por um canal raso e estreito, que possui um baixo fluxo de água, que atravessa uma extensa floresta de mangue. Já na porção oeste, um canal natural entre as ilhas de Jaguanum e Itacuruçá, com profundidade de 30 m, mantém a troca com o mar de maneira regular (BARCELLOS, 1995).

As baías são ambientes costeiros abrigados que conciliam diferentes ecossistemas, apresentando uma elevada biodiversidade (MOLISANI et al., 2004) e a Baía de Sepetiba se insere neste contexto apresentando alta produtividade devido aos influxos continentais e marinhos. A região está na região metropolitana do Rio de Janeiro, sendo considerada excelente alvo para grandes investimentos visando desenvolvimento econômico/ industrial. Estes foram destinados aos setores portuários e industriais, bem como à infraestrutura de acesso, afetando a economia tradicional, desequilibrando os equipamentos já insuficientes da área de saúde e saneamento, aumentando a demografia e degradando intensamente a sua condição ambiental (MORENO \& KATO, 2015).

A Baía de Sepetiba é uma das regiões que passaram bruscamente de Sertão Carioca à área industrial e local de escoamento de commodities minerais, e ainda por cima sem planejamento urbano, algo que certamente influencia diretamente a vida das famílias que ocupam aquele território (WEYRAUCH, 2013). Nestes termos, as mudanças naturalmente resultaram em conflitos, choques culturais decorrentes das distintas formas de perceber, lidar e se apropriar do meio ambiente. Os conflitos socioambientais locais resultam muitas vezes no aumento das pressões por leis e por transformações no Estado e no comportamento das pessoas, visando reconstituição do ambiente, qualidade de vida e de suas existências. Um exemplo interessante, na própria região da Baía de Sepetiba, é a reconstituição da orla resultando no resgate do lazer na praia de Sepetiba, executado pelo Inea, trazendo de volta a urbanização praiana e beneficiando cerca de 40 mil moradores da região (INEA, 2019). A qualidade de vida também se reflete na qualidade dos espaços públicos de lazer (OLIVEIRA \& MACARÓ, 2007). Na região, entre as principais formas de lazer ao ar livre estão as praias e cachoeiras, na maioria das vezes muito afetadas negativamente (COPELAND et al., 2003; FIORI et al., 2013). As crises ambientais também resultam em promoção da Educação Ambiental, fornecendo códigos de comportamentos corretos na vida cotidiana e informações, relacionadas, por exemplo, sobre as ameaças à natureza, à paisagem, à saúde humana e à qualidade de vida urbana, como atividade escolar ou paraescolar, e também através da difusão da informação por diferentes meios de comunicação (SATO \& SANTOS, 1996). A falta de conhecimento sobre a importância do ecossistema funciona como um entrave importante para sua preservação e conservação.

Diante destes pressupostos, este trabalho apresenta uma breve análise da atual situação de degeneração social e ambiental na Baía de Sepetiba. Com base nesta análise foi estudado o nível de conhecimento dos estudantes de Ensino Médio, os danos causados ao seu cotidiano e ao próprio meio ambiente, pelas atividades antrópicas para o desenvolvimento econômico. Um dos desdobramentos mais comuns da poluição ambiental é observado no aumento da incidência de neoplasias. Por este motivo foi feita uma investigação da taxa de mortalidade por câncer no entorno da Baía de Sepetiba. Estes dados em conjunto poderão servir como instrumento de conscientização sobre as possíveis consequências das atividades antrópicas e as ações para proteção e preser- 
vação do meio ambiente, ampliando a percepção da importância destas ações para a promoção da melhoria da qualidade de vida, com sustentabilidade.

\section{METODOLOGIA}

Este trabalho estudou as interferências antrópicas no meio ambiente resultantes do desenvolvimentismo no estado Rio de Janeiro, especificamente na região da Baía de Sepetiba, a partir das informações disponíveis na internet. Além disso, o estudo baseou-se em dados de cunho empírico, envolvendo percepção, conhecimento e preferências de alunos de ensino médio de escolas públicas Estaduais na região da Baía de Sepetiba, submetendo-os a um questionário exploratório.

O Referencial Teórico da pesquisa foi fundamentado no rastreamento de dados nacionais e internacionais derivados de artigos científicos, relatórios técnicos, legislação pertinente e sítios eletrônicos de instituições governamentais e não governamentais, relacionados às alterações antropogênicas na Baía de Sepetiba e suas repercussões negativas.

O questionário é uma abordagem de estudo descritivo correlacional, com dados retrospectivos. A fonte inicial de informações para elaboração do questionário foi o resultado da análise da documentação obtida após levantamento bibliográfico. Antes da distribuição da folha de pesquisa, as turmas foram visitadas, visando explicar brevemente o fundamento da pesquisa. O questionário foi aplicado em maio de 2017, preenchido pelos alunos individualmente e abordou, com linguagem simples e direta, sobre dados gerais - nome da escola, município, bairro, idade, série e turma - e dados específicos para serem respondidos por meio de escolha de alternativas, que eram relacionadas ao cotidiano, lazer, noções sobre o ambiente que frequentavam e as possíveis interferências antrópicas, conforme abaixo.

1- Você costuma ir à praia e/ou à cachoeira quantas vezes no ano?

Alternativas: Nenhuma; 1 à 5 vezes; 6 à 10 vezes; mais de 10 vezes

2- Quais dessas praias e locais de cachoeira você costuma frequentar?

Alternativas: Pedra de Guaratiba; Praia de Sepetiba; Ilha da Madeira; Coroa Grande; Itacuruçá; Muriqui; Praia Grande; Sahy; Ibicuí; Praia do Saco; Conceição de Jacareí; Barra de Guaratiba; Restinga de Marambaia; Praia da Capela; Praia da Brisa; Praia do Cardo; Praia do Recôncavo; Mazomba; Outras

3- Você considera as águas das praias e/ou cachoeiras que você marcou:

Alternativas: Muito limpas; Limpas; Razoavelmente limpas; Sujas; Muito sujas

4- O esgoto da sua escola é:

Alternativas: Tratado e a água limpa é liberada nos rios; Não é tratado e o esgoto é liberado nos rios; Não sei

5- Marque as empresas que fica perto da sua casa ou escola?

Alternativas: TKCSA; Furnas; Cosigua; CSN; Nuclep; Gerdau

6- Você acha que essas empresas:

Alternativas: Não poluem; Poluem moderadamente; São altamente poluidoras; Não sei 
7- Você acha que essas empresas podem poluir somente:

Alternativas: A água dos rios; O solo; A água dos mares; A água e o solo; $\mathrm{O}$ ar, a água dos rios e dos mares e o solo; O ar; Não poluem.

8- Sobre os portos, marque os que você conhece:

Alternativas: Porto Sudeste; Porto de Itaguaí

9- Para você as atividades dos portos (carregamento, descarregamento e tráfego de navios; obras; conserto e limpeza de embarcações)...

Alternativas: São benéficas para o meio ambiente; Prejudicam o meio ambiente de certa forma; Prejudicam muito o meio ambiente; Não sei

As respostas, fornecidas segundo escala pré-definida de 1 a 5 , foram tabuladas em frequências simples. As informações obtidas foram organizadas de forma a possibilitar a descrição da população amostrada, revelando parte de seu cotidiano e características.

A população do estudo foi constituída por alunos de ensino médio do ensino público do Estado do Rio de Janeiro, na área da Baía de Sepetiba. Esta pesquisa foi realizada com alunos de idade entre 14 e 76 anos, de escolas situadas na região litorânea da Baía de Sepetiba. As escolas estão localizadas especificamente no Centro do município de Itaguaí, em Itacuruçá, um distrito do município de Mangaratiba e no bairro Santa Cruz, no município do Rio de Janeiro. 115 alunos estudavam em Santa Cruz período vespertino, 61 em Itaguaí no período noturno e 54 em Mangaratiba, também período noturno, totalizando 230 alunos. A localização aproximada das escolas está sinalizada por ícones com a forma de estrela vermelha na figura 1. Previamente ao estudo, foram obtidas as autorizações dos diretores das Escolas por meio de entrevistas, para que a pesquisa fosse desenvolvida nos recintos. 
Figura 1: Localização das escolas estaduais abordadas nesta pesquisa, marcadas com estrela vermelha.

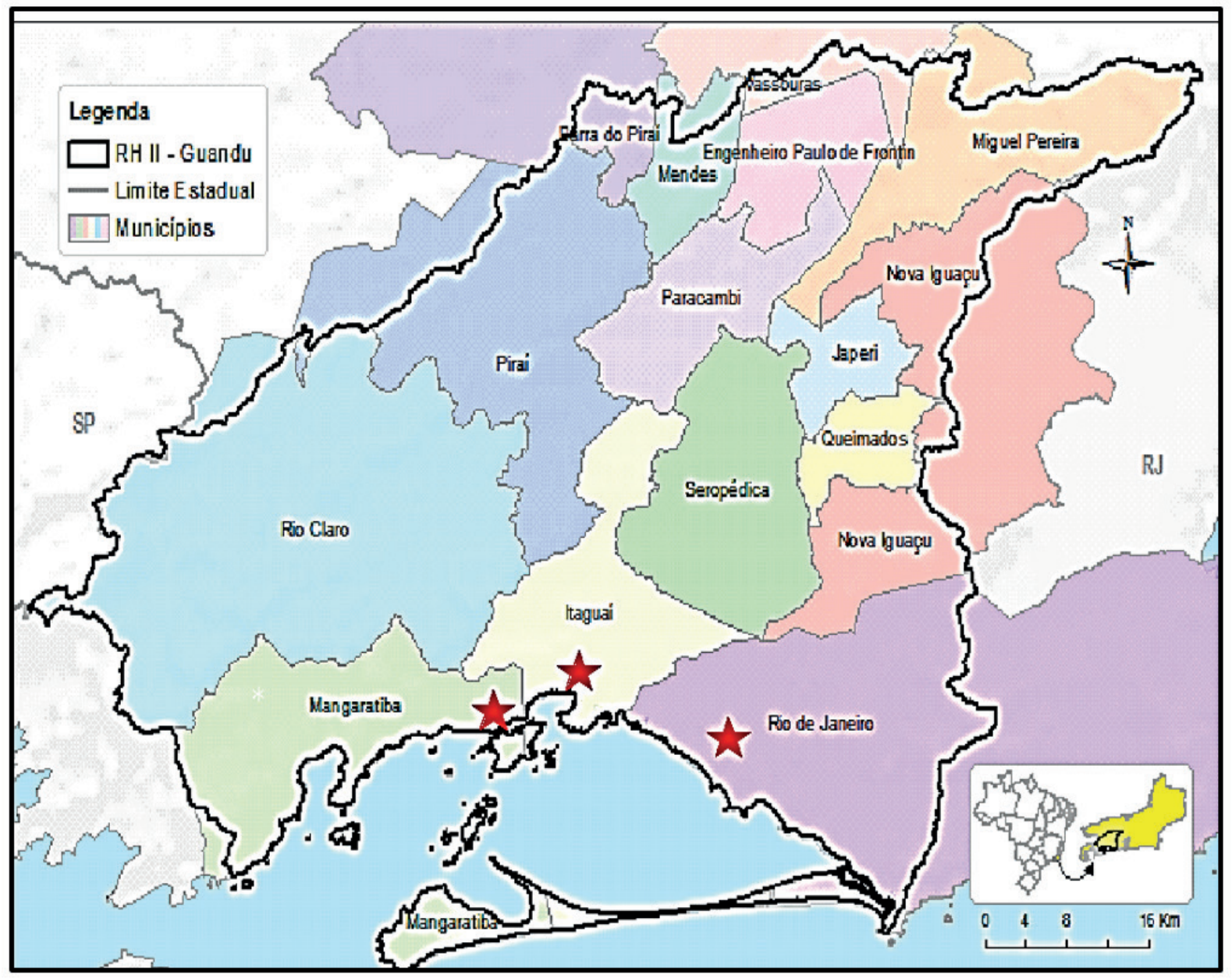

Fonte: (GUANDU, s.d.)

A avaliação das taxas de mortalidade por câncer foi fundamentada nas bases de dados disponibilizados no Atlas de Mortalidade disponibilizado pelo Instituto Nacional de Câncer (https://mortalidade.inca.gov.br/MortalidadeWeb/). O Atlas forneceu a taxa de mortalidade por câncer baseada nas 5 localizações primárias mais frequentes em cada município, como por exemplo, mama, cólon de útero e outras. As taxas fornecidas foram somadas para o cálculo aproximado da taxa de mortalidade por câncer no município estudado.

\section{RESULTADOS E DISCUSSÃO}

\section{1 A problemática ambiental}

Tem sido relatado que o crescimento demográfico da região de Sepetiba se intensificou com a industrialização desde a década de 50 (KATO \& MORENO, 2015). De fato, a ocupação dos espaços litorâneos tem sido estimulada nas últimas décadas por políticas públicas instituídas pelo governo federal, visando desenvolvimento econômico através de intervenções de grande impacto, como a implantação de polos industriais, siderurgias, ampliação de infraestrutura de rodovias, ferrovias e portuárias, usinas de produção de energia elétrica e terminais petrolífero (MORAES, 1999). Em consonância, o governo estadual conferiu prioridade ao desenvolvimento das indústrias e ao Porto de Itaguaí (antigo Porto de Sepetiba) dando suporte ao modelo econômico federal (FIRJAN, 2012). Entretanto, o crescimento econômico sem um gerenciamento apropriado, conciliando os diferentes interesses, pode ter um efeito contrário sobre o desenvolvimento da população, considerando sua qualidade de 
vida, um fenômeno já constatado em outras regiões costeiras, que pelo caráter logístico-estratégico, tem atraído este tipo de investimento, ao longo da história (NETO et al., 2006; MP, 2018).

O primeiro grande investimento ocorreu1959, com a instalação da Companhia Mercantil e Industrial Ingá, que empenhada em produzir lingotes de zinco, produziu refugo líquido que foi despejado na Baía de Sepetiba até 2005. Além disso, o resíduo sólido foi acumulado no terreno da empresa e formou uma montanha avermelhada com 3,5 milhões de m3 de metais pesados, como o chumbo, cobre, cádmio e zinco- (RODRIGUES, 2017). A atividade de pesca artesanal foi amplamente afetada, o que com os demais desdobramentos, levou a um processo de exclusão de parte da sociedade (PAZ \& BARROS, 2013). Em 1996 houve um vazamento em larga escala do dique de contenção de rejeitos, o que acarretou a falência da empresa logo após, em 1998. Ainda assim, a empresa continuou prejudicando gravemente o meio ambiente, até que em 2008 foi arrematada em leilão pela Usiminas, como parte de uma arquitetura política e jurídica para resolver seus passivos ambientais (MME, 2008). A contaminação por metais vem impactando gravemente o ambiente e evidências clínicas comprovam grande variedade de ocorrências resultantes da exposição a essas substâncias químicas (SÁ, 1999; HORTA et al., 2011; TOLENTINO \& SOARES, 2004). A remediação encontra-se atrasada (RODRIGUES \& FREITAS, 2017).

Na década de 1970 foi instalada a Nuclep (Nuclebrás Equipamentos Pesados), estatal destinada à produção de reatores nucleares e peças metalúrgicas de alta precisão. Ainda nesse período instalaram-se também a Fundição Técnica Sul Americana (indústria naval), a Usina Itaguaí (produtora de metais não ferrosos), a Companhia Siderúrgica Nacional e a Companhia Docas do Rio de Janeiro, que ficou encarregada de implantar a White Martins e a Casa da Moeda do Brasil. A Gerdau Cosigua só iniciou a sua produção em 1973 e a Casa da Moeda foi inaugurada em 1984 (MORENO \& KATO, 2015).

A partir dos anos 2000, a Baía de Sepetiba se tornou um dos destinos preferenciais de investimentos públicos e privados. Segundo Kato \& Quintela (2012), o primeiro megaempreendimento foi a instalação da ThyssenKrupp Companhia Siderúrgica do Atlântico (TKCSA) (Ternium Brasil) que incluiu um porto com capacidade de produção de 5,5 milhões de toneladas de aço ao ano. A empresa já foi denunciada diversas vezes devido ao não cumprimento de mais de 100 exigências legais. Como parte da logística dos grandes empreendimentos, foram construídos grandes portos; os portos de Itaguaí e Sudeste estão posicionados na Ilha da Madeira (Itaguaí). O Porto de Itaguaí tem o papel concentrador de cargas e contêineres integrado a rodovias, ferrovias e hidrovias (GUSMÃO, 2012; RODRIGUES \& FREITAS, 2015). O Porto Sudeste está na categoria de portos com Atividade Poluidora e Utilizadora de Recursos Naturais em Alto Grau (INSTITUTO BRASILEIRO DE GEOGRAFIA E ESTATÍSTICA, 2017) e não resulta na geração intensiva de empregos, além de inviabilizar a atividade pesqueira e turística. Porém, entre os impactos resultantes, sobressaem a seca de nascentes de água, produção de lama, poeira e ruído, aumento da prostituição e violência e redução do turismo e pesca, além do aumento do despejo de esgotos (LOPES, 2014).

A construção do Estaleiro e Base Naval também fez parte da logística empresarial local, pois visou a proximidade com empresas como a Nuclep, do Porto de Itaguaí e da Base Aérea de Santa Cruz (PADILHA, 2012). O Prosub-EBN (Programa de Desenvolvimento de Submarinos) contou com licenças de órgãos ambientais, autorizando o desmatamento e alterações de padrões ambientais. A Marinha do Brasil recebeu permissão de aterrar 17,75 hectares, reduzindo área de manguezal, importante criadouro de várias espécies marinhas (LIMA, 2011).

Outro tipo de instalação impactante é a Usina. A Usina Termelétrica de Santa Cruz opera atualmente com gás natural, sendo responsável pela produção de energia que é fornecida para o Rio de Janeiro (FURNAS, 2019), a Usina Hidrelétrica de Fontes e a Usina Hidrelétrica Pereira Passos, em Piraí; todas são importantes geradoras de energia abastecedora da Região Metropolitana do Rio de Janeiro. A energia gerada em uma usina termelétrica é feita por queima de combustíveis, como carvão e gás natural, assim, a localização junto aos locais de consumo implica em economia nos custos de implantação das redes de transmissão, mas também gera impactos ambientais como poluição aérea e hídrica (CASTRO et al., 2012). O projeto de instalação de Usina Termelétrica de Sepetiba em Itaguaí foi motivo de conflitos, em função da supressão de vegetação e realocação de comunidade (VIÉGAS, 2007). 
Embora a Baía de Sepetiba apresente áreas urbanizadas e distritos industriais, seu território atualmente caracteriza-se também por paisagens naturais com baixa ocupação populacional e atividades práticas de agricultura, pesca e turismo ecológico. Pescadores artesanais e agricultores familiares convivem com os impactos dos projetos industriais e com a privatização de recursos naturais. Destaca-se em região próxima, no entorno do canal de São Francisco em Itaguaí e Santa Cruz, a oleicultura e fruticultura, com uso frequente de pesticidas e defensivos agrícolas (SEMADS, 2001). Embora ainda sejam observadas práticas agrícolas, a extração de areias por empresas construtoras, substituiu, em parte, a atividade agrícola em decorrência da industrialização da região. Esta atividade está incluída no quesito de crimes ambientais, principalmente por ocorrer, em grande parte, de forma ilícita. Na extração de areia, há a formação de cavas, nas quais afloram as águas do aquífero Piranema. Estas são consideradas de alta periculosidade e não foram recuperadas como preveem as leis ambientais (ACCAMTAS, 2018). Marques (2011) observou o aumento da solubilidade de metais em formas químicas mais tóxicas em cavas de escavação de areia nos areais presentes em Seropédica. Além disso, atividades de mineradoras e de indústrias de extração de óleo e gás podem dispor no ambiente radionuclídeos e componentes de séries radioativas que promovem um aumento da exposição à radiação natural aos seres vivos (DO RIO et al, 2002).

A problemática ambiental observada na região não parou por aí. A Baía de Sepetiba vem sofrendo com o crescimento populacional que acompanhou a política de desenvolvimento também devido ao aumento da poluição derivada dos rejeitos de esgotos in natura e saneamento básico ineficiente. A região recebe esgoto de mais de um milhão de habitantes, que vivem nos 15 municípios próximos (BRUNO, 2012). A partir do momento em que as cidades crescem e se transformam sem planejamento, crescem também as questões de ordem socioeconômica, os ambientes vulneráveis e problemas de saúde pública (MARANDOLA Jr \& HOGAN, 2004).

A instalação de empreendimentos associada à carência de leis específicas protetoras do meio ambiente, atraso no cumprimento das leis (ROCHA et al., 2010) e falta de equipamentos coletivos e culturais (SILVA, 2016), contribuiu para diferentes formas de degradação ambiental. Entretanto, o desenvolvimento pleno requer infraestrutura adequada, incluindo itens que favorecem melhores condições de vida e a redução de desigualdade, considerando saúde, moradia e educação, além do saneamento básico (BELTRÃO \& SUGAHARA, 2005).

\section{2 A questão social}

Já foi colocado que a Baía de Sepetiba abrange um território de 15 municípios fluminenses, entre eles Itaguaí, Japeri, Paracambi e Nova Iguaçu, que apresentam grandes vulnerabilidades (DESCHAMPS, 2009). A vulnerabilidade está associada a exposição a situações que fragilizam, exclusão e violação de direitos fundamentais, enquanto que o desenvolvimento humano está baseado no ampliação das escolhas . O Índice de Desenvolvimento Humano Municipal (IDHM) é uma medida de desenvolvimento dos municípios, sendo composto de indicadores de três dimensões do desenvolvimento humano: longevidade, educação e renda. $\mathrm{O}$ índice varia de 0 a 1 , sendo que, quanto mais próximo de 1, maior o desenvolvimento humano (PNUD,2018). A tabela 1 mostra a população estimada nos municípios da Baía de Sepetiba e o Índice de Desenvolvimento Humano Municipal (IDHM). 
Tabela 1 - Municípios do território da Baía de Sepetiba totalmente e parcialmente inseridos na bacia da Baía de Sepetiba, relacionados às populações estimadas (IBGE, 2019) e IDHM (2010).

\begin{tabular}{|c|c|c|}
\hline \multicolumn{3}{|c|}{ Municípios do território da Baía de Sepetiba } \\
\hline Nome & População estimada (2019) & IDHM (2010) \\
\hline \multicolumn{3}{|c|}{ Totalmente inserido na Bacia } \\
\hline Engenheiro Paulo de Frontin & 14.002 & 0,722 \\
\hline taguaí & 133.019 & 0,715 \\
\hline Japeri & 104.768 & 0,659 \\
\hline Mangaratiba & 44.468 & 0,753 \\
\hline Paracambi & 52.257 & 0,720 \\
\hline Queimados & 150.319 & 0,680 \\
\hline Seropédica & 82.312 & 0,713 \\
\hline \multicolumn{3}{|c|}{ Parcialmente inserido } \\
\hline Rio Claro & 18.529 & 0,683 \\
\hline Miguel Pereira & 25.538 & 0,745 \\
\hline Mendes & 18.614 & 0,736 \\
\hline Piraí & 29.277 & 0,708 \\
\hline Nova Iguaçu & 821.128 & 0,713 \\
\hline Rio de Janeiro & 6.718 .903 & 0,799 \\
\hline Vassouras & 36.896 & 0,714 \\
\hline Barra do Piraí & 100.374 & 0,733 \\
\hline
\end{tabular}

Fonte: Instituto Brasileiro de Geografia e Estatística (IBGE), 2019.

Os municípios do entorno totalizam 47,5\% da população do Estado do Rio de Janeiro. Com exceção da cidade do Rio de Janeiro, todos os municípios do entorno encontram-se abaixo do IDH do Estado (0,761), de acordo com o IBGE (2019). A cidade do Rio de Janeiro é marcada por realidades contrastantes e a parte da Zona Oeste, que é a adjacente à Baía de Sepetiba (Santa Cruz, Sepetiba, Guaratiba, Barra de Guaratiba e Pedra de Guaratiba), está entre os que possuem os piores indicadores de pobreza e renda do Estado Rio de Janeiro, reunindo grande número de famílias em situação de vulnerabilidade ambiental e social, com alguns dos piores indicadores sociais do Estado do Rio de Janeiro (ROCHA \& ALBUQUERQUE, 2007). Parte dessas famílias dependem de atividades informais para viver com serviços relacionados ao turismo, à agricultura de subsistência e à pesca (MORENO \& KATO, 2015).

O IDH é também uma medida comparativa da qualidade de vida da população. Contudo, a qualidade de vida é um conceito multidimensional, que abrange aspectos materiais e não materiais, e pode estar relacionada à satisfação no que diz respeito ao acesso à alimentação, saúde, segurança, educação, às condições no trabalho, à cultura e ao lazer (MARTINS, 2002). Além disso, existem vários indicadores que medem qualidade de vida, mas que também são considerados como socioambientais, por exemplo, o acesso à água tratada, ao esgoto e à coleta de resíduos, deixando claro que as condições que afetam a pobreza e a degradação ambiental estão estreitamente conectadas. Acselrad (2004), destaca que a região da Baía de Sepetiba possui populações de baixa renda e com menor poder de decisão sobre o próprio território, produzindo conjunturas de injustiça que se refletem nos índices de saúde, educação, renda e qualidade de vida geralmente precários. De fato, boa parte da região é carente de equipamentos de saúde, cultura e monitoramento ambiental administrador de poluição (SILVA, 2016).

\section{3 A percepção de estudantes sobre o seu meio ambiente}

Um levantamento de dados foi feito também a partir da análise do perfil dos alunos frequentadores de escolas da região, baseado na aplicação de questionário com perguntas sobre hábitos dos alunos, permitindo a identificação de pontos críticos para conscientização sobre seu meio ambiente. A escola pode ser enxergada 
como um reflexo da sociedade por grandes estudiosos como Bourdieu \& Passeron (1975) e ainda tem sido descrita como a referência mais importante para a vida dos estudantes no mundo contemporâneo, sustentando a organização da sociedade em geral (CAVALIERE, 2007). Deste modo, os resultados obtidos chamam atenção por representar a relação da comunidade local com o meio ambiente.

A avaliação foi feita com 230 alunos com idade entre 14 e 76 anos, sendo que a idade de maior prevalência foi de 16 anos (83\%). A figura 2A, revela que mais de 90\% dos estudantes, frequentam praias e/ou cachoeira regularmente sendo que, cerca de metade (48\%) desta amostra, mais de 5 vezes ao ano. Os alunos frequentam praias e cachoeiras geralmente na própria Baía de Sepetiba, sendo que as três localidades mais visitadas foram as praias de Itacuruçá, Muriqui e Praia Grande (Figura 2B). Estes dados são preocupantes quando confrontados com as informações publicadas pelo Boletim de Balneabilidade de Praias da Costa Verde (INEA, 2018), que mostrou que a balneabilidade das praias de Mangaratiba, Saco, Ibicuí, Muriqui, Itacuruçá, Coroa Grande e parte da Praia Grande apresentaram-se impróprias para o banho no ano de 2016, indicando que há uma considerável exposição às condições adversas decorrentes dos contaminantes ambientais, tanto dos indivíduos amostrados, quanto de suas famílias e amigos. É fato que a população frequenta as praias e cachoeiras mesmo quando há claras evidências de alteração do meio, como lixo, retirada de vegetação e construções. Quase $90 \%$ dos alunos relataram não saber sobre o tratamento de esgotos (Figura 2C). Além do Boletim sobre a balneabilidade e da presença de lixo, construções e valões, facilmente são observadas em algumas praias, como por exemplo, a que foi flagrada em novembro de 2016 na praia do Sahy, em Mangaratiba (figura 2D). Dados anteriores já têm mostrado que a região da Baía de Sepetiba sofre em decorrência de uma série de ocorrências, como o acidente ambiental pela Companhia Ingá; o aumento do tráfego de embarcações e dragagem devido ao Porto de Itaguaí, a transposição de águas do rio Paraíba do Sul para o rio Guandu que aumentou a carga de sólidos na baía, a poluição por esgoto doméstico (ROCHA et al., 2010), a retirada da mata ciliar, as atividades de mineração e fraca gestão ambiental (BRUNO, 2012). A instalação de empreendimentos associada à carência de leis específicas protetoras do meio ambiente, o atraso no cumprimento das leis ou ausência dessas, saneamento básico improfícuo e crescimento populacional, também contribuíram para a degradação ambiental (ROCHA et al., 2010). 
Figura 2: Frequência de idas à praia ou cachoeira expressa em 0,1 a 5 ou >5 vezes por ano (2A); praias ou cachoeiras frequentadas pelos alunos (2B); conhecimento sobre tratamento de água e esgoto em sua região (2C); flagrante em praia do Sahy, Mangaratiba (2D).

A

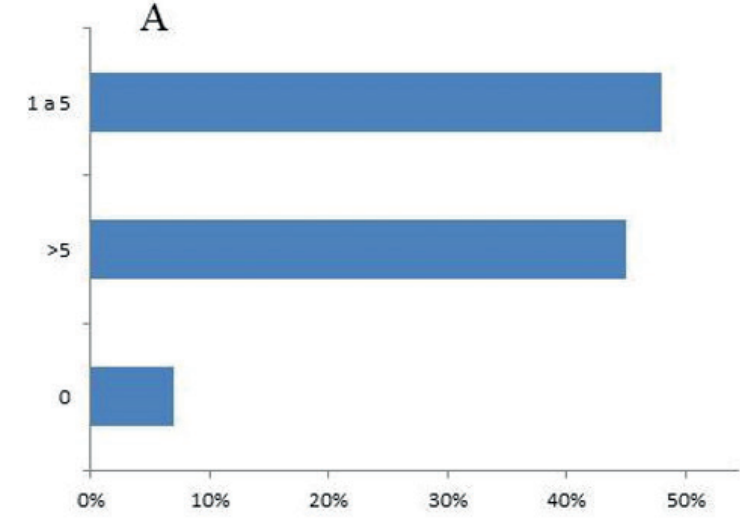

B

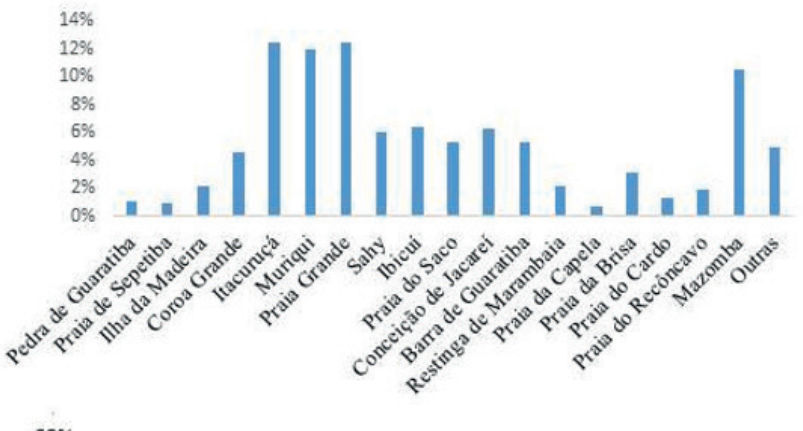

$60 \%$

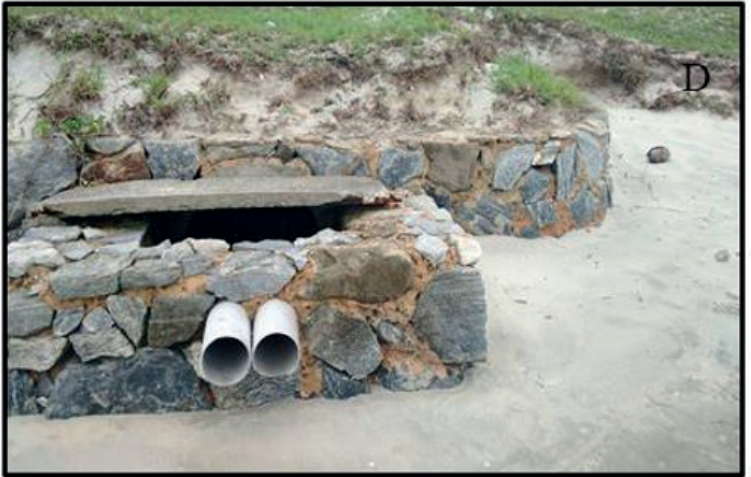

Fonte: autoria própria.

Não obstante, os alunos de Santa Cruz/Rio de Janeiro ainda demonstraram, em sua maioria, estar satisfeitos com as condições ambientais das áreas de lazer frequentadas pelos próprios, considerando as águas razoavelmente limpas, limpas ou até mesmo muito limpas, totalizando 70\% dos indivíduos. Além disso, mais da metade da população estudantil amostrada desconhece pelo menos três das grandes empresas mencionadas no questionário, o que tem um significado ampliado considerando a existência de uma quantidade muito elevada de empresas na região da Baía de Sepetiba. Menos da metade da população acha que as empresas mencionadas são grandes poluidoras, porém, em contradição, 73\% acham que as mesmas podem poluir o ar, a água, o solo e o ar (figura 3AB). Além disso, quase a totalidade da população amostrada tem ciência da existência do Porto de Itaguaí, porém, praticamente desconhecem o Porto Sudeste. Praticamente a metade da população (46\%) acha que os portos são benéficos ao meio ambiente. 


\section{Figura 3 A-B: Distribuição percentual dos alunos com relação ao seu conhecimento ou opinião sobre o efeito poluidor dos empreendimentos locais.}

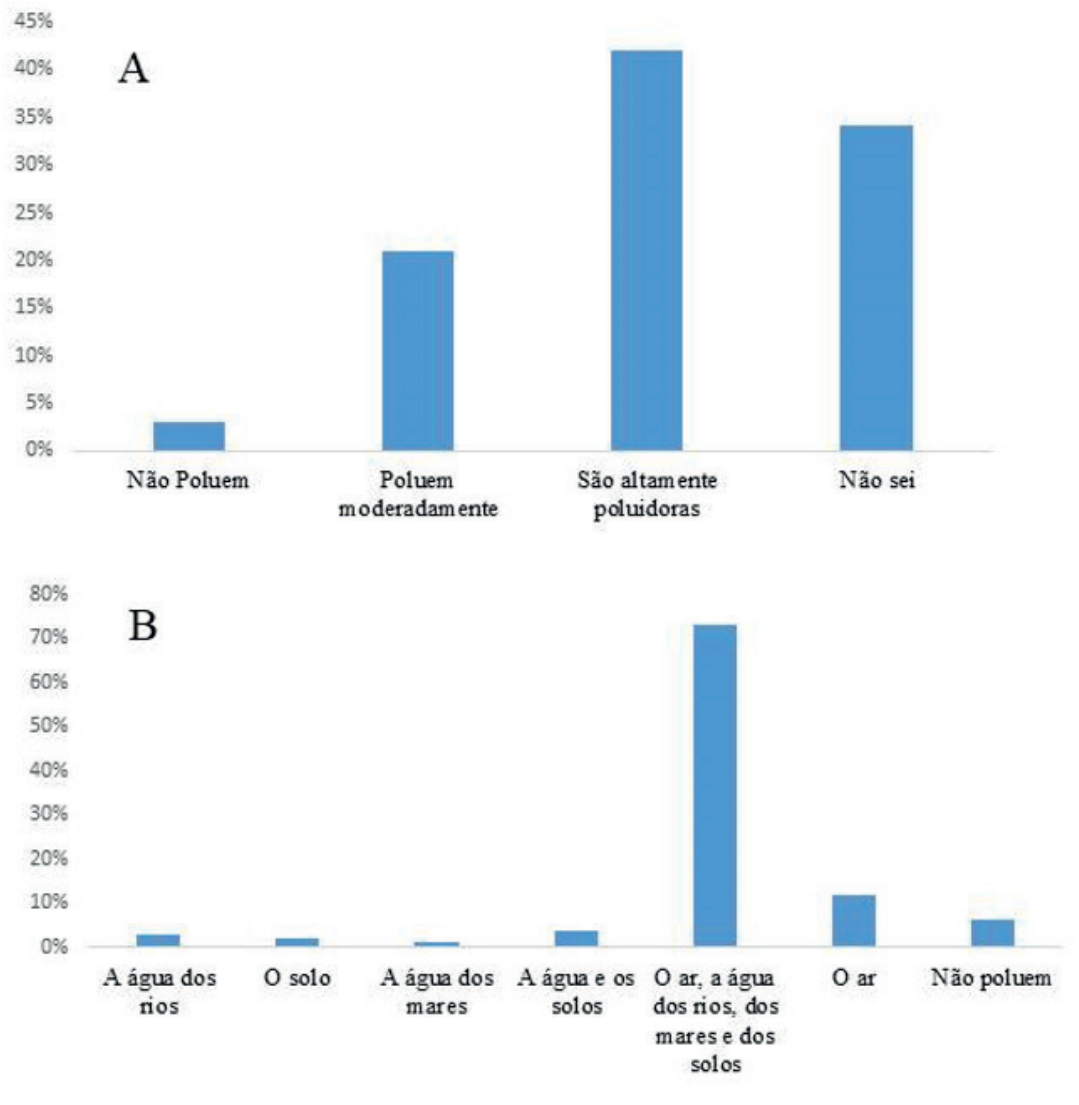

Fonte: autoria própria.

Aparentemente, os impactos ambientais e sociais que estes empreendimentos podem causar ainda precisam ser melhor compreendidos. Um exemplo está nas respostas controversas sobre os Portos, já que 74\% dos alunos informarem que os Portos "prejudicam o meio ambiente de certa forma" e que as atividades portuárias são "benéficas ao meio ambiente”.

O resultado do questionário permite constatar que a maioria da população da Baía de Sepetiba pode estar ignorando que o processo de industrialização esteja envolvido na redução de sua qualidade de vida, decorrente da alteração do meio onde vivem; de modo geral, não possui verdadeiro entendimento social e político sobre as consequências degradantes que a mudança de paisagem, sem os devidos cuidados com o meio ambiente, podem trazer para os mesmos (ZBOROWSKI, 2008).

\section{4 O impacto sobre a saúde}

Vários trabalhos anteriores têm relatado que uma das consequências mais marcantes das interferências antropogênicas, decorrentes da politica de desenvolvimento de Estado, focalizada na Baía de Sepetiba, é o aumento de poluentes considerados cancerígenos derivados de atividades industriais (CSA, 2009; FONSECA et al., 2013; LINDOLFO, 2015)

Um exame no banco de dados do Instituto Nacional do Câncer permite identificar o número de mortos por câncer em períodos e localidades específicas. Os indicadores são oriundos, principalmente, dos Registros de Câncer e do Sistema de Informações sobre Mortalidade. Considerando os tipos mais recorrentes de câncer, de forma generalizada, foi possível identificar as frequências de casos de mortalidade, por câncer, em algumas localidades e em períodos definidos. Neste trabalho foram escolhidos os períodos dos 1996 e 2017, tendo em 
vista que 1996 foi o ano em que ocorreu o acidente ambiental pela Cia Ingá Mercantil (SILVESTRE, 2005) e que 2017 é a data máxima em que este dados são disponibilizados pelo Atlas de Mortalidade do INCA.

Vale destacar que os municípios de Itaguaí, Mangaratiba, Rio de Janeiro e, um pouco mais atrás, Seropédica, encontram-se emoldurando os principais empreendimentos do polo industrial da Baía de Sepetiba (figura 4). A tabela 2 apresenta a taxa de mortalidade por câncer, registrada nos anos 1996 e 2017, nos municípios de Itaguaí, Mangaratiba, Seropédica, Rio de Janeiro, Niterói e Vassouras. Niterói e Vassouras foram também analisados devido ao seu afastamento da região da Baía de Sepetiba, sendo que um município possui alto IDHM (Niterói; 0,837) e o outro possui IDHM semelhante ao de Itaguaí (Vassouras; 0,714). Pode ser observado que o número de mortes por câncer cresceu de modo alarmante no período estudado em Itaguaí, Mangaratiba e Seropédica, sendo este último caso ainda mais aberrante. Na cidade do Rio de Janeiro houve uma redução de 15,9\%, porém, vale ressaltar que não há dados disponibilizados neste Atlas sobre a incidência de mortes por câncer em locais como Santa Cruz e Sepetiba, bairros deste município que estão incluídos na bacia da Baía de Sepetiba. Além disso, a redução da incidência de mortalidade por câncer, no Rio de Janeiro, provavelmente está diretamente associada ao fato de o município ser uma das principais referências em atenção oncológica no Estado (SES-RJ/Plano Estadual de Saúde).

Outros empreendimentos foram instalados na região da Baía de Sepetiba e há heterogeneidade no tipo de iniciativa em cada um dos locais, assim como no impacto e no grau de degradação ambiental, significando que este resultado é decorrente de um somatório dos efeitos das diferentes interferências antrópicas, mas ainda assim são dados que evidenciam o tamanho do desastre ambiental, assim como a necessidade de conscientização visando estímulo ao autocuidado e às práticas de redução de danos ao meio ambiente. A Constituição Federal de 1988 traz o direito ao meio ambiente saudável e equilibrado para o uso comum, com o objetivo de preservar para a geração atual e as futuras. Atitudes transformadoras sobre a forma de pensar e de agir que servem como um meio para garantir direitos fundamentais.

Figura 4: Principais empreendimentos do Polo Industrial da Baía de Sepetiba.

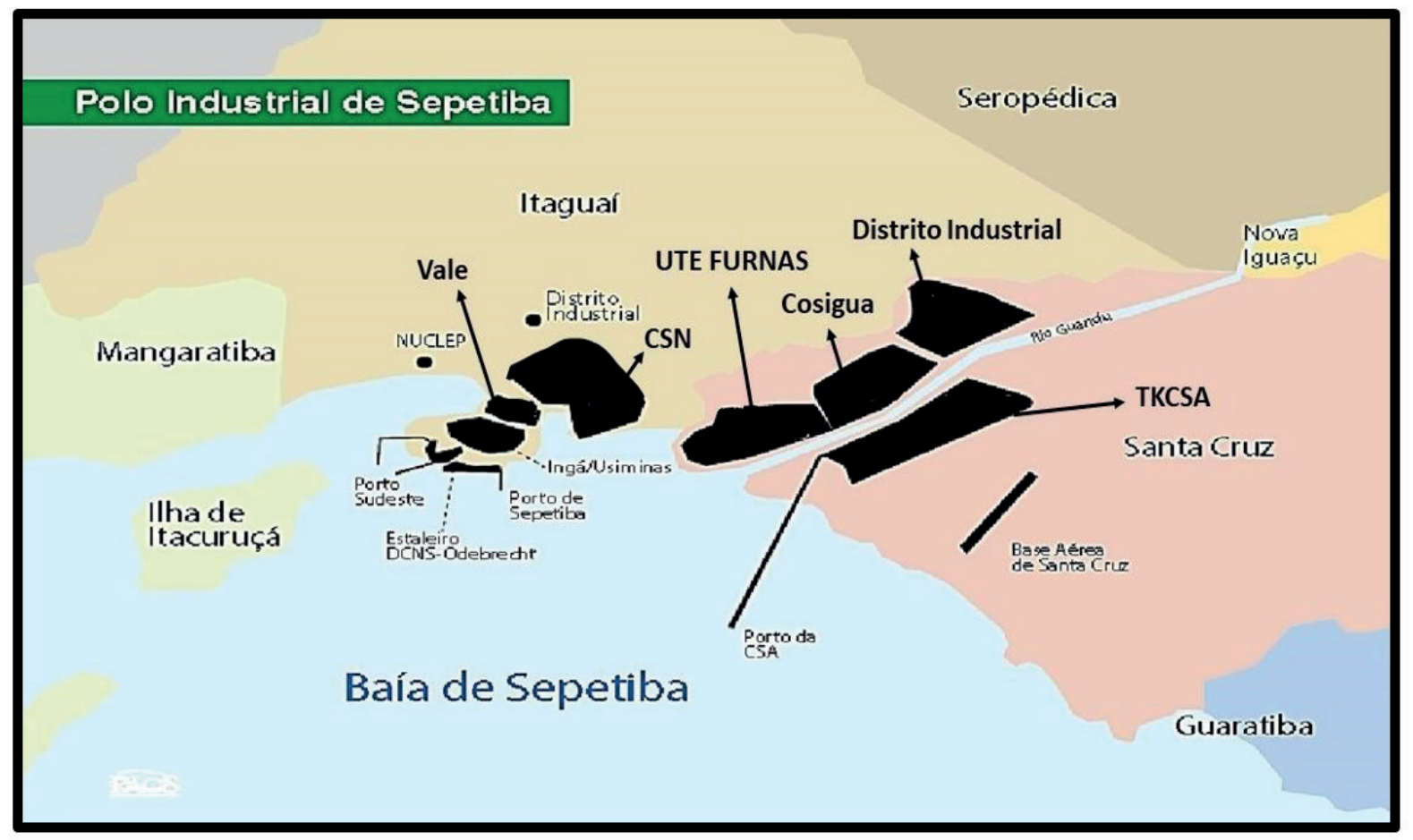

Fonte: Moreno \& Kato, 2015. 
Tabela 2 - Taxas de mortalidade por câncer em 2017, ajustadas por idade, pela população mundial, por 100.000 homens e mulheres, entre 1996 e 2017, nos municípios Itaguaí, Mangaratiba, Seropédica, Rio de Janeiro, Niterói e Vassouras.

\begin{tabular}{lccc}
\hline \multicolumn{1}{c}{ Município } & $\mathbf{1 9 9 6}$ & $\mathbf{2 0 1 7}$ & Mudança \\
\hline Itaguaí & 29,95 & 53,08 & $\uparrow 77,2 \%$ \\
\hline Mangaratiba & 22,8 & 38,7 & $\uparrow 69,9 \%$ \\
\hline Seropédica & 14,49 & 34,13 & $\uparrow 135 \%$ \\
\hline Rio de Janeiro & 50,42 & 42,39 & $\downarrow 15,9 \%$ \\
\hline Niterói & 44,16 & 45,23 & $\uparrow 2,4 \%$ \\
\hline Vassouras & 59,7 & 51,22 & $\downarrow 14 \%$ \\
\hline
\end{tabular}

Fonte: Atlas de Mortalidade do Inca.

\section{CONSIDERAÇÕES GERAIS}

A Baía de Sepetiba, outrora um belo ecossistema da Mata Atlântica, de manguezais, rios e mar, hoje constrange-se em uma paisagem de vulnerabilidade ambiental e social. Uma Baía de Sepetiba felizmente ainda bastante heterogênea, mas repleta de situações conflitantes, decorrentes, principalmente, de vários empreendimentos ambientalmente danosos.

A escola pode ser um espelho da sociedade e uma amostra dos estudantes de escolas públicas locais revelou que esta sociedade parece alheia à profundidade do tema relacionado às alterações em seu meio, provocadas pelos empreendimentos que deveriam estar focados no desenvolvimento da região de modo pleno. O crescimento econômico sem um gerenciamento apropriado pode ter um efeito contrário sobre o desenvolvimento da população, sujeitando territórios e modos de vida às mais diversas práticas agressiva, além de dramáticos problemas de saúde pública e aumento da mortalidade. A verdade é que a população da Baía de Sepetiba é testemunha de uma crise ambiental complexa, ainda que não tenha plena ciência do mesmo, invocando assim a produção e disseminação de reflexões críticas e aumento do conhecimento sobre os benefícios que podem ser alcançados pela proteção e preservação do meio ambiente.

Este trabalho, além de funcionar como instrumento de conscientização, poderá servir para formar agentes sociais difusores da educação ambiental. É urgente a necessidade de transformações nos comportamentos, nos valores e práticas do cotidiano, incluindo o seu lazer, que possam repercutir positivamente na redução de desigualdades sociais e na melhoria do meio ambiente, saúde e qualidade de vida da população.

\section{Agradecimentos}

A todos aqueles que contribuíram, de alguma forma deste trabalho, como as instituições de ensino do Estado do Rio de Janeiro, especialmente à instituição de ensino UEZO (Fundação Centro Universitário Estadual da Zona Oeste), essencial no processo de formação e experiência profissional. 


\section{REFERÊNCIAS}

ACCAMTAS Rio de Janeiro 2018. Degradação Ambiental: areais de Seropédica. Disponível em: http://www. accamtas.com.br/p/degradacao-ambiental-seropedica.html. Acesso em: 15 de mar. 2018.

ACSELRAD, H.; HERCULANO, S.; PÁDUA, J. A. (Org.). Justiça ambiental e cidadania. Rio de Janeiro: Relume Dumará, 2004.

BARCELLOS, C. 1995. 148 p. Geodinâmica de Cádmio e Zinco na Baía de Sepetiba. Tese (Doutorado em Geoquímica Ambiental). Universidade Federal Fluminense, Rio de Janeiro.

BELTRÃO, K. I.; SUGAHARA, S. Infra-estrutura dos domicílios brasileiros: uma análise para o período 1981-2002. Rio de Janeiro: IPEA, Texto para discussão, n. 1077, 2005.

BOURDIEU, P.; PASSERON, J. A Reprodução: elementos para uma teoria do sistema de ensino. [Trad. Reynaldo Bairão]. Rio de Janeiro: Francisco Alves Editora S/A(Série Educação em Questão, 1975.

BRASIL. Constituição (1988). Constituição da República Federativa do Brasil. Brasília: Senado, 1988.

BRUNO, A. A. G. Água, fonte de vida. In: TUBBS FILHO, D.; ANTUNES, J. C. O.; VETTORAZZI, J. S. (Org.). Bacia Hidrográfica dos Rios Guandu, da Guarda e Guandu-Mirim - Experiências para a gestão dos recursos hídricos. Rio de Janeiro: INEA, 2012. v. I, p. 11-15.

CASTRO, S.M., ALMEIDA, J.R.; RODRIGUES, M.G. Valoração de Dados Ambientais da Geração Termelétrica:Usina de Santa Cruz/RJ. Revista Internacional de Ciências v. 2, n. 2, 2012.

CAVALIERE, Ana Maria. Tempo de escola e qualidade na educação pública. Educ. Soc., Campinas, v. 28, n. 100, p. 1015-1035, Oct. 2007. Available from <http://www.scielo.br/scielo.php?script=sci_arttext\&pid=S010173302007000300018\&lng=en\&nrm=iso $>$. access on 17 Jan. 2020.

COMITÊ DAS BACIAS HIDROGRÁFICAS DOS RIOS GUANDU, DA GUARDA E GUANDU-MIRIM - CBH Guandu. Revista temática do Comitê Guandu: Guandu Conhecimento - Guandu Verde Nº1, Fevereiro 2013.

COPELAND G; MONTEIRO, T; COUCH, S; BORTHWICK, A. Water quality in Sepetiba Bay, Brazil. Marine Environmental Research 55:5,385-408, 2003

CSA - Companhia Siderúrgica do Atlântico (TKCSA). Impactos e Irregularidades na Zona Oeste do Rio de Janeiro. PACS, 2ª Edição. Rio de Janeiro, 2009.

DESCHAMPS M. V. Vulnerabilidade Socioambiental das Regiões Metropolitanas Brasileiras. Observatório das Metrópoles - Ippur/Fase. Ed Letra Cap 2009.

DO RIO, M.A.P.; AMARAL, E.C.S.; FERNANDES, H.M.; ROCHEDO, E.R.R. Environmental radiological impact associated with non-uranium mining industries: a proposal for screening criteria. Journal of Environmental Radioactivity, 59:1, Pages 1-17 - 2002.

FEDERAÇÃO DAS INDÚSTRIAS DO ESTADO DO RIO DE JANEIRO (FIRJAN). Decisão Rio Investimentos 2012 - 2014. Sistema FIRJAN. 2012

FIORI, C.S.; RODRIGUES A.PC.; SANTELLI, R. E., CORDEIRO, R. C., CARVALHEIRA, R. G.; ARAÚJO P. C., CASTILHOS, Z. C.; BIDONE, E. D. Ecological risk index for aquatic pollution control: a case study of coastal water bodies from the Rio de Janeiro State, southeastern Brazil. Geochimica Brasiliensis 27:1, 2013. 
FONSECA, E.F., BAPTISTA NETO, J.A. \& SILVA, C.G. Heavy metal accumulation in mangrove sediments surrounding a large waste reservoir of a local metallurgical plant, Sepetiba Bay, SE, Brazil. Environ Earth Sci 70: 643, 2013 . https://doi.org/10.1007/s12665-012-2148-3

FURNAS. Termelétrica de Santa Cruz chega modernizada aos 51 anos. Rio de Janeiro, 2019. Disponível emhttps://www.furnas.com.br/noticia/103/noticias/157

GUANDU (Comitê da Bacia Hidrográfica). Seropédica, [s.d.]. Disponível em: http://www.sigaguandu.org.br/ siga-guandu/saibaMais. Acesso em: 15 mai. 2018.

GUSMÃO P. Elementos para a construção de uma agenda para a gestão ambiental da área de influência do porto de Itaguaí - RJ. Confins, 15. 2012. Disponível em : http://journals.openedition.org/confins/7747.

HORTA, M. A. P.; FERREIRA, A. P.; LUZARDO A. J. R., BRIGNOL V.; BRASIL, V. Í.; FARO A.R. M.C.; PINTO, W. J. Análise de risco da ingestão de cádmio por consumidores de pescado em lagoa costeira subtropical, Baía de Sepetiba-SE, Brasil - Revista Brasileira de Promoção da Saúde 24, n. 1, 46-53, (2011).

INEA. Reconstituição da orla resgata o lazer na praia de Sepetiba. Disponível em: http://www.inea.rj.gov.br/ Portal/Noticias/OBRA_ESGOTAMENTOSANITMAROMBA. Acesso em 02/01/2019

INSTITUTO BRASILEIRO DE GEOGRAFIA E ESTATÍSTICA. Panorama. Rio de Janeiro, 2017. Disponível em: https://cidades.ibge.gov.br/brasil/rj/mangaratiba/panorama. Acesso em 17 mar. 2018.

INSTITUTO ESTADUAL DO AMBIENTE. Boletim de Balneabilidade de Praias - Região da Costa Verde $\mathbf{N}^{\circ}$ 4. Rio de Janeiro, 2018. Disponível em: http://www.inea.rj.gov.br/ar-agua-e-solo/balneabilidade-das-praias/. Acesso em 17 mar. 2018.

INSTITUTO NACIONAL DE CÂNCER. Atlas On-line de Mortalidade. Rio de Janeiro, 1996. Disponível em: https://www.inca.gov.br/MortalidadeWeb/pages/Modelo07/consultar.xhtml. Acesso em 06 ago. 2018.

KATO, K. \& QUINTELA, S.. Companhia siderúrgica do atlântico: impactos e irregularidades na Zona Oeste do Rio de Janeiro. Rio de Janeiro, Pacs. Disponível em http://www.bibliotecadigital.abong.org.br/handle/11465/688. 2012

LIMA, A. P. M. Supressão de vegetação e compensação ambiental em quatro empreendimentos no município de Itaguaí - RJ. 2011. 44f. Monografia (Engenharia Florestal) - Universidade Federal Rural do Rio de Janeiro, Seropédica.

LINDOLFO, N. S. O impacto ambiental decorrente do processo industrial na área e nos arredores da Companhia Mercantil e Industrial Ingá - Bairro da Ilha da Madeira (Município de Itaguaí, RJ). Khora, Revista Transdisciplinar, Rio de Janeiro, v. 2, n. 2, maio 2015.

LOPES, Erika Ferreira. O Porto Sudeste e a Vulnerabilidade Socioambiental na Ilha da Madeira, Itaguaí, RJ. 2014. 95 f. Dissertação (Mestrado em Saúde Pública) - Escola Nacional de Saúde Pública Sergio Arouca, Fundação Oswaldo Cruz, Rio de Janeiro, 2014.

MARANDOLA Jr E.; HOGAN, D.J. Natural hazards: o estudo geográfico dos riscos e perigos. Ambiente \& Sociedade. ANPPAS - Revista Ambiente e Sociedade, v. 7, n. 2, p. 95-110, 2004.

MARQUES, E. D. Impactos da mineração de areia na bacia sedimentar de Sepetiba, RJ. 2010. 203f. Tese (Doutorado em Geociências) - Universidade Federal Fluminense, Niterói.

MARTINS, C. A. S.; NOGUEIRA, N. O.; RIBEIRO, P. H.; RIGO, M. M.; CANDIDO, A. O. A dinâmica de metais-traço no solo. Revista Brasileira de Agrociência, Pelotas, v. 17, n. 3-4, p. 383-391, 2011. 
MARTINS C. H. B. Pobreza, meio ambiente e qualidade de vida: indicadores para o desenvolvimento humano sustentável. Indic. Econ. FEE, Porto Alegre, v 30, n. 3, p 171-188, dez 2002.

MINISTÉRIO DO MEIO AMBIENTE (MME). Ministro vai replicar no país fórmula que resolveu maior passivo ambiental do RJ (2008). https://www.mma.gov.br/informma/item/4900-ministro-vai-replicar-no-paisformula-que-resolveu-maior-passivo-ambiental-do-rj.html. Disponível em 09/01/2019.

MINISTÉRIO DO PLANEJAMENTO, DESENVOLVIMENTO E GESTÃO. Estratégia Nacional de Desenvolvimento Econômico e Social (Documento para consulta pública). http://www.planejamento.gov.br/ assuntos/planeja/endes. Disponível em 05/01/2019.

MOLISANI, M. M., R. V. MARINS, W. MACHADO, H. H. M. PARAQUETTI, E. D. BIDONE \&, L. D. LACERDA. Environmental changes in Sepetiba Bay, SE Brazil. Regional Environmental Change, Volume 4: 17-27(2004).

MORAES, A.C.R. Contribuições para a Gestão da Zona Costeira do Brasil: elementos para uma geografia do litoral brasileiro. São Paulo, Ed. Hucitec, 1999.

MORENO, C., KATO, K., 2015. Baía de Sepetiba: fronteira do desenvolvimentismo e os limites para a construção de alternativas. PACS - Instituto Políticas Alternativas para o Cone Sul, Rio de Janeiro, 124 p. www.pacs.org.br

NETO, A. C. L.; LEGEY, L. F. L.; GONZÁLEZ-ARAYA, M. C.; JABLONSKI, S. A system dynamics model for the environmental management of the Sepetiba bay wateshed, Brazil. Environ Manage. V.38, 879 - 888 p. 2006.

OLIVEIRA, L. A.; MASCARÓ, J. J. Análise da qualidade de vida urbana sob a ótica dos espaços públicos de lazer. Ambiente Construído, Porto Alegre, v. 7, n. 2, p. 59-69, abr./jun. 2007.).

ORGANIZAÇÃO DAS NAÇÕES UNIDAS (ONU). Programa das Nações Unidas para o Desenvolvimento (PNUD). Disponível em: http://www.pnud.org.br/home/. Acesso em: 17 de nov. 2018

PADILHA, L. PROSUB-EBN - Estaleiro e Base Naval em Itaguaí. Defesa Aérea \& Naval. 4 dez. 2012. Disponível em: http://www.defesaaereanaval.com.br/prosub-ebn-estaleiro-e-base- naval- em-itaguai/. Acesso em: 12 jan. 2018.

PAZ, M. O. C.; BARROS, R. F. Modernização e usos do território: impactos no cotidiano dos pescadores artesanais da Ilha da Madeira (RJ). In: 11º Seminário Nacional Espaços Costeiros, 3-6 out. 2013, Salvador. Anais. Salvador, 2013.

PLÁCIDO, P. O.; NEFFA, E. M. V. C.; GUIMARÃES, M. O Território de Itaguaí/RJ como “Zona De Sacrifício" ou "Paraíso de Poluição". V Seminário de Justiça Ambiental, Igualdade Racial e Educação. Rio de Janeiro -2015.

ROCHA, D. S.; CUNHA, B. C. A.; GERALDES, M. C.; PEREIRA, S. D.; ALMEIDA, A. C. M. Metais pesados em sedimentos da baía de Sepetiba, RJ: implicações sobre fontes e dinâmica da distribuição pelas correntes de maré. Geochimica Brasiliensis, Rio de Janeiro, v. 24, n. 1, p. 63-70, 2010.

ROCHA, S.; ALBUQUERQUE, R.C. Pobreza extrema no Rio de Janeiro: Uma espacialização alternativa. Econômica, Rio de Janeiro, v.9, n.1, p.63-88, junho 2007

RODRIGUES, S.C.A. Baía de Sepetiba: Um Enclosure no Século XXI - análise histórica de um processo de alteração ambiental. Tese (doutorado em Planejamento Urbano e Regional) UFRJ, 245p (2017). 
RODRIGUES, S. C. A.; FREITAS, M. B. Sepetiba: Cercamentos e impactos ambientais em escala industrial. In: XVI Encontro Nacional da Associação Nacional de Pós-Graduação e Pesquisa em Planejamento Urbano e Regional: Espaço, Planejamento e Insurgências, 18-22 mar. 2015, Belo Horizonte. Anais... Belo Horizonte, 2015.

RODRIGUES, S. C. A.; FREITAS M. B. Baía de Sepetiba Hoje: A Possível Guanabara do Amanhã. In: XXXI Congreso Alas. Las encrucijadas abiertas de America Latina: La sociologia em tempos de câmbio. Uruguay. (2017) Disponível em http://alas2017.easyplanners.info/opc/tl/2530_silvio_cesar_alves_rodrigues.pdf

RONCARATI, H.; CARELLI, S. G. Considerações sobre o estado da arte dos processos geológicos cenozóicos atuantes na Baía de Sepetiba, p. 13 - 36. In: RODRIGUES, M. A. C.; PEREIRA, S. D.; SANTOS, S. B. (eds.), Baía de Sepetiba - Estado da Arte. Rio de Janeiro, p.26,. 2012.

SÁ, P.G.S.. Contaminação do ambiente marinho por metais pesados e suas implicações sobre comunidades de pescadores artesanais. Tese (Doutorado em Saúde Pública) Escola Nacional de Saúde Pública, Fundação Oswaldo Cruz, Rio de Janeiro, 274 pp.1999.

SATO, M.; SANTOS, J.E. Agenda 21 em Sinopse. São Carlos: Programa Integrado de Pesquisa, PPG-ERN/ UFSCar, 1996. Versão espanhola publicada em Guadalajara: SEMARNAP \& PNUD, 1997.

SECRETARIA de ESTADO de SAÚDE do RIO de JANEIRO. Plano Estadual de Atenção Oncológica do Rio de Janeiro. Rio de Janeiro: SES-RJ. 2017

SEMADS. (2001), Bacias Hidrográficas e Recursos Hídricos da Macrorregião Ambiental 2 - Bacia da Baía de Sepetiba. Projeto PLANAGUA SEMADS/GTZ. Cooperação Técnica Brasil-Alemanha. Rio de Janeiro

SILVA, C. A., SUIAMA, S. G. Baía de Sepetiba - Riscos à natureza e aos coletivos humanos na metrópole do Rio de Janeiro. Expansão urbano-industrial e logística na Baía de Sepetiba e conflitos territoriais com a pesca artesanal: história recente da produção social da periferia metropolitana. Rio de Janeiro. Editora Letra Capital Editora LTDA, 2016.

SILVESTRE, D. R. Jean Pierre Leroy. Revista Rio de Janeiro, Rio de Janeiro, n. 16-17, maio-dez, 2005.

TOLENTINO, J; SOARES J. L. Companhia Mercantil e Industrial Ingá: “a bomba de Itaguaí”. In: ACSERALD, H. organizador. Conflito social e meio ambiente no Estado do Rio de Janeiro. Rio de Janeiro: Relume Dumará, p. 93-226, 2004.

TUBBS, D. ; MARQUES, E.D.; GOMES, O.V.O.;SILVA-FILHO, E.V. Impacto da Mineração de Areia sobre a Química das Águas Subterrâneas, Distrito Areeiro da Piranema, Municípios de Itaguaí e Seropédica, Rio de Janeiro. Revista Brasileira de Geociências 41(3): 472-485, setembro de 2011.

VIÉGAS, R. N. Conflitos ambientais no Rio de Janeiro: um estudo dos casos do projeto da usina termelétrica (UTE) de Sepetiba e do projeto da Companhia Siderurgia do Atlântico (CSA): Um estudo dos casos do projeto da Usina Termelétrica (UTE). 2007. 128f. 120. Dissertação (Mestrado em Sociologia e Antropologia) - Universidade Federal do Rio de Janeiro.

WEYRAUCH, CLEIA SCHIAVO. De sertão à zona industrial. In: Revista Ágora, Vitória,n. 17:13-31, 2013.

ZBOROWSKI, M. B. Conflitos ambientais na Baía de Sepetiba: o caso dos pescadores atingidos pelo processo de implantação do complexo industrial da Companhia Siderúrgica do Atlântico (ThyssenKrupp CSA) 2008. 254 f. Dissertação (Mestrado em Psicossociologia de Comunidades e Ecologia Social) - Instituto de Psicologia, Universidade Federal do Rio de Janeiro, Rio de Janeiro, 2008. 